\title{
Research on Measurement Technology of Length and Area Based on COMPASS Positioning
}

\author{
Xinliang $\mathrm{Cao}^{1, *}$ and HongxiaYang ${ }^{2}$ \\ ${ }^{1}$ School of Physics and Electronics Information, Yan'an University, Yan'an 716000, China \\ ${ }^{2}$ School of Architecture and Engineering, Yan'an University, Yan'an 716000, China \\ ${ }^{*}$ Corresponding author
}

\begin{abstract}
This paper studies the Compass Positioning and WI-FI positioning etc. for single point positioning and measurement of distance between two points in the error range. As a reference, GPS measurement data with accurate positioning is shown else. On this basis, calculation rules of the area measurement by which the Compass system of irregular region mining point positions into regular polygon approximation is explored, and then the rule method is used to calculate the cumulative area measurement for complex and irregular terrain. It can be shown with irregular area. The experimental data and the measurement results show that the relative error of Bei-dou Positioning length, within distance between $100-200 \mathrm{~m}$,is less than $5 \%$, and area measurement error of the regular shape is within $3 \%$.
\end{abstract}

Keywords-area measurement; GIS; compass positioning; positioningaccuracy; error

\section{INTRODUCTION}

Beidou satellite navigation system of China also known as BDS or Compass is the global satellite positioning and navigation system, rendering China the third nation with independent property rights of this system in the world after the United States, Russia. After years of development and improvement, it has gradually developed into a mature system. At present, the global satellite navigation system GPS of the United States occupies the leading position in the use of location monitoring ${ }^{[1]}$ and geodetic mapping ${ }^{[2]}$. Map of Baidu etc., expanded on the basis of GPS, is relatively mature technologically, and measurement of the length of two points on the earth and the area is more accurate. Nevertheless, the Compass, still being potential for substantial development and wider application ${ }^{[3]}$, is only used in the location of services ${ }^{[4]}$, deformation monitoring ${ }^{[5,6]}$, waters and sea measurements ${ }^{[7]}$.To break the shackles and manipulation of GPS technology, there is an urgent need to expand the application of the Compass system and to make full and effective use of Compass signal resources. Based on the Compass positioning data, this paper takes the GPS positioning data with high positioning accuracy as the reference ${ }^{[8]}$ and studies the measurement technology of two-point distance and specific surface area.

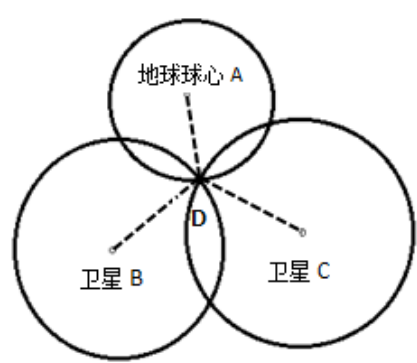

FIGURE I. THREE BALL INTERSECTION SCHEMATIC DIAGRAM

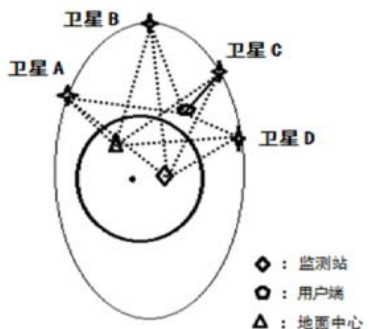

FIGURE II. PASSIVE POSITIONING SCHEMATIC

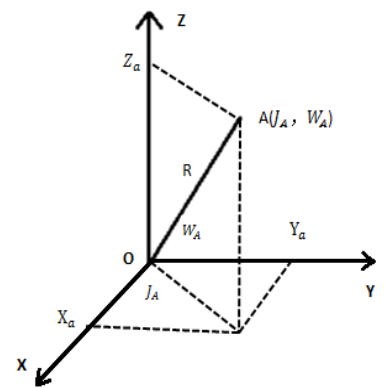

FIGURE III. THE ANGLES OF LATITUDE AND LONGITUDE AT SPATIAL COORDINATES

Compass 1 satellite positioning system, based on the principle of three-ball intersection, is the binary positioning system that can achieve active positioning ${ }^{[1]}$. The principle is to make two on-orbit working satellite shown in figure 1 as point $\mathrm{B}, \mathrm{C}$ whose two coordinates are known as the centers of the circle as and $\mathrm{B}$ and $\mathrm{C}$, and to make circles respectively with radius of the distance between satellite and client side, forming three intersecting sphere with the earth, and then the intersection point $\mathrm{D}$ is determined as the client side. Client $\mathrm{D}$, 
through the ground control center, applies to B and C for two satellites positioning signal, while at the same time sending microwave signal and measuring satellite transmission time back and forth to calculate the distance between the satellite to the client.

As the COMPASS I positioning accuracy is low, China has developed COMPASS II satellite with active positioning and similar passive positioning function of the GPS. Firstly, a reasonable distribution of space satellite system needs to be established, so that most parts of the client can observe more than three satellites, afterwards, continuous observation to the satellites by the receiver is made. When the master station sends a ranging signal, the satellite will return the short message carrying the satellite clock message to the receiver and calculate the pseudo range from the satellite to the receiver. The quaternary system of equations is established involving modified pseudo range and the spatial coordinate of four satellites (Located in a position A, B, C, and D shown in Fig. 2)and the clock difference between satellite and receiver (T), to solve the location of the positioning.

\section{GEOMETRIC MEASUREMENT AND EXPERIMENTAL ANALYSIS BASED ON COMPASS LOCATING}

\section{A. Space Cartesian Coordinate Transformation for single Point Positioning}

Assuming that the latitude and longitude of two points -A and $\mathrm{B}$ are $\left(\mathrm{J}_{A}, W_{A}\right)$ and $\left(\mathrm{J}_{B}, W_{B}\right)$ respectively with $\mathrm{A}$ marked in Figure 3 , and then latitude and longitude of $A$ and $B$ is changed into space Cartesian coordinates $s^{[9,10]}$. $\mathrm{R}$ is the radius of the earth $^{[11]}$, as shown in equation (1)

$$
\pi \operatorname{ovv} \tau \text { A: }\left\{\begin{array}{c}
\mathrm{X}_{a}=\mathrm{R} \cdot \cos W_{A} \cdot \cos \mathrm{J}_{A} \\
\mathrm{Y}_{a}=\mathrm{R} \cdot \cos W_{A} \cdot \sin \mathrm{J}_{A} \\
Z_{a}=\mathrm{R} \cdot \sin W_{A}
\end{array}\right.
$$

Similarly, $\mathrm{X}_{b}$ and $\mathrm{Y}_{b}$ andZ $\mathrm{Z}_{b}$ of $\mathrm{B}$ points are obtained. Then the space distance between two points $\mathrm{A}$ and Bias as follows:

$$
l_{A B}=\sqrt{\left(X_{a}-X_{b}\right)^{2}+\left(Y_{a}-Y_{b}\right)^{2}+\left(Z_{a}-Z_{b}\right)^{2}}
$$

The same point (shown in Figure 4 and 5) of positioning data are obtained by testing the different systems ${ }^{[13]}$, and the GPS and other systems on the same point positioning difference is calculated according to (1), (2). After the location of the positioning point are changed, the two groups of data are obatined aslisted in Table 1 through another experiment.

TABLE I. THE POSITIONING ACCURACY COMPARISON BETWEENCOMPASS, WI-FIAND GSM (REFER TO GPS)

\begin{tabular}{cccc}
\hline Absolute error & Compass & WI-FI & GSM) \\
\hline $\begin{array}{c}\text { The difference } \\
\text { distance1(m) }\end{array}$ & 5.106641 & 45.070693 & 127.756433 \\
$\begin{array}{c}\text { The difference } \\
\text { distance2(m) }\end{array}$ & 4.033424 & 55.687001 & 121.160689
\end{tabular}

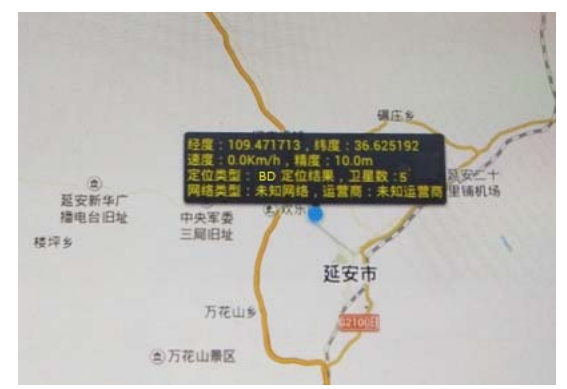

FIGURE IV. THE LOCATION OF THE RECEIVER POSITIONED BY THE BEIDOU

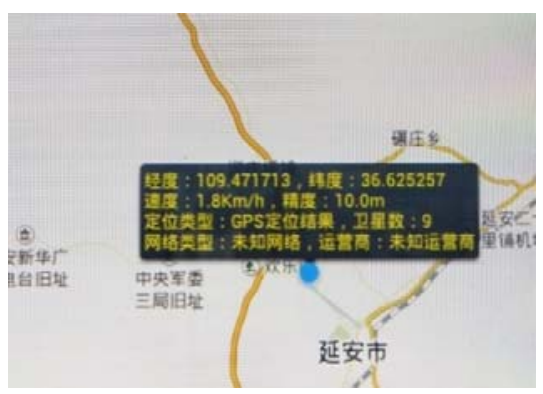

FIGURE V. THE LOCATION OF THE RECEIVER POSITIONED BY THE GPS

According to Table 1, the distance between the Compass positioning and the GPS positioning position is within $6 \mathrm{~m}$, and the absolute error of the positioning is kept within a certain range. Compared with the WI-FI positioning ${ }^{[12]}$ and the GSM positioning, Compass positioning accuracy is relatively higher that can be relatively accurate for actual distance, while the error of GSM positioning is bigger in measurement of the length and area, thus making the data lose its meaning.

\section{B. Length Measurement of Compass}

On the GNSS experimental development platform two latitude and longitude of two points are first measured, and then latitude and longitude are covert into spatial coordinates according to formula (1) ${ }^{[13]}$ before two points distance in the space is calculated. Based on the distance measured by GPS as the reference, the error of the two groups of length measurement by the Compass's and WI-FI's data with GPS's is analyzed and compared, as shown in Table 2.

The error of the position of the position depends on the absolute error of the length measurement, while the relative error of the length measurement is related to the measurement distance: the longer the distance is, the smaller the relative error is. It can be seen from Table 2 that the relative error of the two-point distance between $100 \mathrm{~m}$ and 200 is within $5 \%$, while the relative error of WI-FI is more than $20 \%$. the length of the measured data by Compass compared to WI-FI positioning can approximate the actual length of the distance. 
TABLE II. COMPASS / WI-FI POSITIONING LENGTH MEASUREMENT

\begin{tabular}{ccccc}
\hline \multicolumn{2}{c}{ Measurement mean } & $\begin{array}{c}\text { The length of the } \\
\text { measurement (m) }\end{array}$ & $\begin{array}{c}\text { Absolute } \\
\text { error( m) }\end{array}$ & $\begin{array}{c}\text { Relative } \\
\text { error (\%) }\end{array}$ \\
\hline Compass & NO.1 & 168.012220 & 5.106641 & 0.029498 \\
& NO.2 & 104.832101 & 4.033424 & 0.037050 \\
\multirow{2}{*}{$\begin{array}{c}\text { GPS(as } \\
\text { reference) }\end{array}$} & NO.1 & 173.118861 & 0 & 0 \\
& NO.2 & 108.865525 & 0 & 0 \\
WI-FI & NO.3 & 101.610000 & 55.687001 & 0.354025 \\
& NO.4 & 147.980000 & 45.070694 & 0.233466 \\
\multirow{2}{*}{ GPS(as } & NO.3 & 157.297001 & 0 & 0 \\
reference) & NO.4 & 193.050693 & 0 & 0 \\
\hline
\end{tabular}

C. Area Measurement

\section{1) Triangular area measurement by Compass}

Through the experiment, the latitude and longitude of the three vertices are measured, and the length of the three sides a, $\mathrm{b}$ and $\mathrm{c}$ is obtained by the formula (2). The triangular area $\mathrm{S}$ is calculated from the Helen formula (3) to obtain the triangular area of the Compass, WI-FI, as shown in Table 3.

$$
\begin{gathered}
\mathrm{S}=\left\{\left([ ( \mathrm { a } + \mathrm { b } + \mathrm { c } ) / 2 ] \cdot \left([(\mathrm{a}+\mathrm{b}+\mathrm{c}) / 2]^{1 / 2}\right.\right.\right. \\
-\mathrm{a}) \cdot([(\mathrm{a}+\mathrm{b}+\mathrm{c}) / 2]-\mathrm{b}) \cdot)\}
\end{gathered}
$$

TABLE III. COMPASS AND WI-FI POSITIONING TRIANGULAR AREA MEASUREMENT AREA ERROR

\begin{tabular}{ccccc}
\hline \multicolumn{2}{c}{ Test methods } & $\begin{array}{c}\text { Measurement } \\
\text { area }\left(\boldsymbol{m}^{2}\right)\end{array}$ & $\begin{array}{c}\text { Absolute } \\
\text { error }\left(\boldsymbol{m}^{2}\right)\end{array}$ & $\begin{array}{c}\text { Relative } \\
\text { error } \\
\mathbf{( \% )}\end{array}$ \\
\hline \multirow{2}{*}{ Compass } & NO.1 & 8578.776920 & 113.743890 & 0.013085 \\
& NO.2 & 5030.243378 & 60.206897 & 0.011827 \\
GPS(as & NO.1 & 8692.520810 & 0 & 0 \\
reference) & NO.2 & 5090.450275 & 0 & 0 \\
& NO.3 & 4960.310000 & 1011.383889 & 0.169363 \\
WI-FI & NO.4 & 7501.530100 & 1529.769832 & 0.169385 \\
& NO.3 & 5971.693889 & 0 & 0 \\
GPS(as & NO.4 & 9031.299832 & 0 & 0 \\
\hline
\end{tabular}

It can be seen from Table 3 that the relative GPS measurement error of the Compass positioning to the triangular area is less than $2 \%$, while the relative error of the survey results of the Compass compared to the WI-FI is relatively smaller with the relative larger error of the WI-FI measurement more than $10 \%$. This is not the best choice for measuring the area.

\section{2) Measurement of Multilateral Area by COMPASS}

For the measurement of the polygon regular area, longitude and latitude of each vertex are measured before the polygonal regions with $>3$ sides is divided into $n-2$ triangular regions. Then, based on the equation (2), each edge to tall to $2 n-3$ is calculated according to the latitude and longitude conversion of space coordinates. Finally the area of each triangular area is obtained and accumulated into polygon are a according to the equation (3).
Table 4 is the regular quadrilateral measurement data of the area by the Compass. It can be seen from the table that regular shape of the error measurement is within $2 \%$.

TABLE IV. QUADRILATERAL AREA MEASUREMENTS

\begin{tabular}{lccc}
\hline & NO.1 & NO.2 & NO.3 \\
\hline Measured value $\left(m^{2}\right)$ & 36242.782355 & 82244.719254 & 30167.985717 \\
Reference value $\left(m^{2}\right)$ & 35794.29969 & 80551.82268 & 29864.80418 \\
Absolute error $\left(m^{2}\right)$ & 448.48266 & 1692.89658 & 303.18154 \\
Relative error $(\%)$ & 0.012529 & 0.021016 & 0.010152 \\
\hline
\end{tabular}

3)Irregular area measurement by compass

Conventional calculation of the irregular area is approximated by the regular area ${ }^{[114,15,16]}$, and the area can be obtained from the regular's. The table 5 is a regular processing of irregular circle area, where the radian of circular evenly is divided, approximating for four, five, hexagon area error.

TABLE V. THE COMPARISON OF THE POLYGONAL AREA OF THE APPROXIMATION CIRCLE AREA

\begin{tabular}{cccccc}
\hline The number of edges & 4 & 5 & 6 & $\ldots$ & 20 \\
\hline Relative error & $36.30 \%$ & $24.30 \%$ & $17.20 \%$ & $\ldots$ & $1.64 \%$ \\
\hline
\end{tabular}

In Table 5, when the circular area is approached by the polygon area, the more vertices are selected, the closer the polygon area is to circle area ${ }^{[5]}$, and the larger number of side length and small triangle area needs to be calculated, which further leads to complex data processing. In the actual measurement, the appropriate number of points needs to be selected according to the error requirements.

The calculation of other irregular area contours is selected appropriate number of points to calculate the distance from a certain point to another point, thus the area of a small triangular area is obtained. By accumulating those small triangle areas, it can be approximated as an irregular area.

\section{CONCLUSION}

On the basis of discussing the difference between the single position of the Compass and the GPS positioning, the latitude and longitude is transformed into the spatial coordinates to directly measure and calculate the space distance of two points. In the area measurement, the irregular area is approximated to the regular region that is divided into several small triangular regions. The length of each edge depending on the latitude and longitude is firstly calculated, and then the area of the small triangular area is calculated by Helen's formula to obtain polygon area. The experimental data show that the relative error is all within $5 \%$ for the measured distance and the area result. For the irregular area, the more points are selected from the outline, the closer the approximation of regular area is to the irregular area. In length and area measurement, the curve of the arc distance on the surface of the earth is approximated as distance of two points for the space, so the method is more accurate to measure the short distance between two points on the earth. Since the initial data obtained from the measurement are the longitude and latitude of the measured point, the measurements of distance and area of the complex landscape with spatial characteristics are actually the projection values in 
the horizontal plane ${ }^{[17]}$, so this method is limited to the approximate horizontal plane measurement.

A more accurate measurement of the complex area of the geomorphic area ${ }^{[18,19]}$ also requires "elevation" and other influencing factors ${ }^{[20,21]}$, which relies on breakthroughs in the precisement of GNSS elevation measurement ${ }^{[22,23,24]}$.

\section{ACKNOWLEDGMENT}

Foundation support: National Natural Science Foundation, China (Grant No.61661049); Science and Technology Program of Shaanxi Province, China (Grant No.2016GY-138); Science and Technology Program of Education Department of Shaanxi China (Grant No.16JK1851).

\section{REFERENCES}

[1] WANG Qing-ping,GUANYu-mei,WANG Zi-yan,et aL.2014. Comparative on interpolation algorithms of three-dimensional coordinates ofthe GPS satellitebit. Progress in Geophysics (in Chinese),29(2):0573-0579.

[2] WANG Shijin,BEI Jinzhong,GU Shouzhou, et al. Relative Positioning of Combined BDS /GPS and Its Accuracy Analysis. Bulletin of Surveying and Mapping (in Chinese), 2014( 5) :1-4.

[3] LI Xiaolong. Real-time GIS Data Mode Supporting Dynamic Data Management and Spatiotemporal Process Simulation [J] .ActaGeodaeticaetCartographicaSinica (in Chinese). 2017,46(3):402.

[4] XIAO Yugang, JIANG Weuoing,CHENHua. et al. Research and Realization of Deformation Monitoring Algorithm with Millimeter Level Precision Based on Compass Satellite Navigation System. ActaGeodaeticaetCartographicaSinica. (in Chinese)2016,45(1):16-21.

[5] JIANG Weiping, LIU Hongfei, LIU Wanke, et al. CORS Development for Xilongchi Dam Deformation Monitoring. Geomatics and Information Science of Wuhan University (in Chinese), 2012,37(8):949-952.

[6] ZHAO Dan-yang, SUN Yue-qiang, BAI Wei-hua, et al.Design and Implementation of A Three Dimensional Data Analysis System for Airborne GNSS-R Based on GIS.Remote Sensing Information (in Chinese). 2016,30(2):120-123.

[7] Yang Y X, Li J L, Wang A B, et al. Preliminary assessment of the navigation and positioning performance of BeiDou regional navigationsatellite system. Science China: Earth Sciences, 2014.57: 144-152.

[8] ZHANG Rui, YANG Yuanxi,ZHANG Qin, et al. Contribution Analysis of BDS/GPS Combined Orbit Determination Geomatics and Information Science of Wuhan University (in Chinese),2017,42(5):600-607.

[9] Wei N, Shi C, Liu J N. Effect of surface loading and heterogeneous GPS network on Helmert transformation. Chinese J. Geophys.( in Chinese). 2016,59(2):484-493.

[10] FANG Xing, ZENG Wen Xian, LIU Jinnan et al. A General Total Least Squares Algorithm for Three-dimemsional Coordinate Transformation. ActaGeodaeticaetCartographicaSinica (in Chinese), 2014, 43(11):1139-1143.

[11] WU Qun-yong, Z HANG Ai - guo, XU Qi - $\mathrm{f}$ eng, et al Analysis of the Precision on GPS Mobile Positioningand Positioning based on Mobile Network. GNSS World of china, 2010,(5):33-37.

[12] LUI Gough,GALLAGHER T,LI Binghao,et al. Differences in RSSI Readings Made by Different Wi-Fi Chipsets-A Limitation of WLAN Localization[C]. 2011IEEE International Conference on Localization and GNSS( ICL-GNSS), 2011 ( 9) : 53-57.

[13] LI Bofeng, SHEN Yunzhong, ZHANG Xingfu, et al. Seamless Multivariate Affine Error-in-variables Transformation and Its Application to Map Rectification [J]. International Journal of Information Science, 2013,27(8):1572-1592.

[14] XU Peiliang, LIU Jingnan,, SHI Chuang. Total Least Squares Adjustment in Partial Errors-in-variables Models: Algorithm and Statistical Analysis[J]. Journal of Geodesy, 2012, 86(8):661-675.
[15] FANG Xing, Weighted Total Least Squares: Necessary and Sufficient Conditions, Fixed and Parameters [J]. Journal of Geodesy,2013,87(8):733-749.

[16] SCHAFFRIN B, FELUS Y A. On the Multivariate Total Least-square Approach to Empirical Coordinate Transformation Three Algorithms[J]. Journal of Geodesy,2008,82(6):373-383.

[17] Wahr J. Khan S A. Dam T. et al. The use of GPS horizontals for loading studies, with applications to northern California and southeast Greenland[J]. Journal of Geophysical Research: Solid Earth,2013,118(4):1795-1806.

[18] Wang L S. Chen C. Zou R. et al. Using GPS and GRACE to detec seasonal horizontal deformation caused by loading of terrestrial water: A case study in the Himalayas. Chinese Journal Geophysics (in Chinese) 2014, 47(6):1792-1804.

[19] Zhang L J, Jin S G, Zhang T Y. Seasonal variations of Earth's surface deformation estimated from GPS and satellite gravimetry. Journal of Geodesy and Geodynamics (in Chinese). 2012, 23(2):32-38.

[20] Fang M, Dong D N, Hager B H. Displacements due to surface temperature variation on a uniform elastic sphere with its centre of mass stationary[J]. Geophysical Journal International, 196(1):194-203.

[21] Tesmer V, Steigenberger P, van Dam T, et al. Vertical deformations from homogeneously processed GRACE and global GPS long-term series [J]. Journal of Geodesy, 2011,85(5):291-310.

[22] LONG Xiao-min, ZHAO Chun-mei, DING Kun, et al. A Method of Improving Geometric Accuracy of Forest Fire Monitoring by Satellite Imagert Based on Terrain Features. Remote Sensing Information(in Chinese) ,2016, 31(6):10-16.

[23] Wei N, Shi C , Liu J N.Annual variations of 3-D surface displacements observed by GPS and GRACE data: a comparison and explanation. Chinese J. Geophys.(in Chinese). ,2015,58 (9):3080-3088.

[24] MA Hongmei, WANG Miaomiao, LIU Yong. Spatial Scale Effect of Land Cover Based on Multi-source Remote Sensing Data. Remote Sensing Information (in Chinese) ,2017, 32(2):155-161 